\title{
Bioelectrical Activity of Vastus Medialis and Rectus Femoris Muscles in Recreational Runners with Anterior Knee Pain
}

\author{
by \\ Piotr Gawdaํ. Michat Ginszt ${ }^{1}$, Magdalena Zawadka1, \\ Maria Skublewska-Paszkowska², Jakub Smołka², Edyta Eukasik², Piotr Majcher ${ }^{1}$
}

\begin{abstract}
Patellofemoral pain syndrome (PFPS), the most common source of knee pain among physically active individuals, is defined as anterior knee pain involving the patella and retinaculum that excludes other intraarticular and peri-patellar pathology. Differences in the activation and endurance of the quadriceps components, causing an imbalance in the forces controlling patellar tracking during flexion and extension in the knee joint, appear to be the most commonly reported risk factors for PFPS. The aim of this study was to determine the differences in bioelectric activity of vastus medialis and rectus femoris muscles during half knee bend position in runners with PFPS. The sample comprised 20 recreational runners ( 15 males, 5 females; aged $27 \pm 5$ years) reporting knee pain and diagnosed with PFPS. The age- and sex-matched control group consisted of recreational runners who did not report knee pain. The myon electromyographic system was used to determine the changes in the electromyographic median frequency during a half squat position. The decrease in the median frequency of vastus medialis and rectus femoris muscles was significantly greater in runners with PFPS in comparison to the control group ( $p<0.01$ for right and left vastus medialis and right rectus femoris; $p<0.05$ for left rectus femoris). There is a relationship between knee pain related to PFPS and the imbalance of bioelectric activity of vastus medialis and rectus femoris muscles. Achieving the muscular balance within the thigh muscles can be an important factor in the rehabilitation process of PFPS.
\end{abstract}

Key words: PFPS, surface electromyography, muscle fatigue, runners.

\section{Introduction}

Patellofemoral pain syndrome (PFPS), the most common source of knee pain among physically active individuals, is defined as anterior knee pain involving the patella and retinaculum that excludes other intraarticular and peri-patellar pathology (Dixit et al., 2007; Raid, 1993). Moreover, PFPS symptoms cause many runners to limit their physical activities (Blønd and Hansen, 1998). The etiology of PFPS is multifactorial and includes overuse, trauma, muscle dysfunction, and patellar hypermobility. Lower knee extension strength, causing imbalances in forces controlling patellar tracking during flexion and extension in the knee joint (Dixit et al., 2007), appears to be the most commonly reported risk factor for PFPS (Lankhorst et al., 2012). The unbalanced action of the quadriceps components and deficiencies in the activity of the dynamic muscle stabilizers of the knee, have been considered the most important biomechanical pathogenesis of PFPS (Giles et al., 2013; Kalytczak et al., 2016; Nunes et al., 2013). In relation to running, both footwear and running style can influence knee angular impulse, which can affect the development of PFPS (Cheung et al., 2006; Stefanyshyn et al., 2006). In addition, the development of PFPS may be related not only to physical, but also psychological factors such as anxiety, depression, pain catastrophizing, and kinesophobia (Domenech et al., 2013).

\footnotetext{
1 - Medical University of Lublin, Lublin, Poland.

2 - Lublin University of Technology, Lublin, Poland.
}

Authors submitted their contribution to the article to the editorial board.

Accepted for printing in the Journal of Human Kinetics vol. 66/2019 in March 2019. 
Knee ligaments are the main static stabilizers of the joint and the knee musculature plays a dominant role in dynamic stabilization referred to as "patellar tracking". (Dixit et al., 2007). Forces on the patella during walking range from $1 / 4$ to $1 / 3$ of body mass, during stair climbing they reach three times body mass and during squatting even seven times body mass (Reilly and Martens, 1972). Moreover subjects with PFPS demonstrate significantly frequent pain when descending and climbing stairs (52.63\%), and during squatting $(68.42 \%)$ in comparison to the subjects who do not suffer from knee pain (Liporaci et al., 2013).

A study using surface electromyography (sEMG) revealed that during the squat, the primary muscles acting about the knee carrying out concentric knee extension and eccentric knee flexion are quadriceps muscles (Schoenfeld, 2010). In addition, the rectus femoris (RF) activity increases when the trunk is more straighten, decreases with trunk forward displacement, and is the highest when the knee is in about $90^{\circ}$ flexion (Schoenfeld, 2010; Souza and Powers, 2009). Higher activity of vastus medialis muscle (VMO) was observed during pedaling cycles in comparison with RF muscle activity (da Silva et al., 2016). Moreover, the RF muscle was the first to present signs of fatigue during maximum contraction in comparison to VMO muscle (Simões et al., 2008).

Anterior knee pain in subjects with PFPS is also often related to an imbalance in the lower limb muscles (Jones and Bampouras, 2010; Knapik et al., 1991), which has been linked to abnormal lower limb biomechanics (Cichanowski et al., 2007; Souza and Powers, 2009) and quadriceps muscle activation failure (Hart et al., 2010). Differences in the activation of the quadriceps heads during contraction have also been observed among subjects with PFPS (Carry et al., 2010). Moreover, quadriceps muscle endurance is significantly lower in subjects with PFPS (Yosmaoglu et al., 2013). Hence, muscular activity and endurance imbalance between the quadriceps muscle groups may have an effect on the abnormal patellar tracking and thus contribute to the development of PFPS.

Thus, the aim of this study was to determine the differences in bioelectric activity of vastus medialis and rectus femoris muscles during the half squat position in recreational runners with PFPS.

\section{Methods}

This study was approved by the ethics committee of the Medical University of Lublin, Poland (KE-0254/331/2015) and was in accordance with the Declaration of Helsinki for Human Research. All study subjects were informed about the procedures they would undergo and gave their informed consent to participate in the tests.

The sample comprised 20 recreational runners (15 males, 5 females; aged $27 \pm 5$ years) reporting bilateral knee pain for at least 2 months and diagnosed with PFPS. The diagnosis of PFPS was established on the basis of clinical evaluation according to diagnostic criteria used by Miao et al. (2015). Exclusion criteria included current or previous record of other knee disorders, lower limb surgery or trauma, and neurological disorders.

An age- and sex-matched control group consisted of recreational runners who did not report current knee pain, had no history or evidence of knee pain, trauma, surgery, or other lower extremity disease. All subjects practised running for about $30 \mathrm{~min}$ twice per week and their average running experience was 3 years.

All the tests were conducted in the morning to decrease the influence of the variability of bioelectrical activity of muscle. A 16-channel modular Wi-Fi myon EMG system, compatible with myon ProEMG software, was used for recording at a sampling rate of $1000 \mathrm{~Hz}$. EMG data were filtered between 5 and $500 \mathrm{~Hz}$. The $\mathrm{Ag} / \mathrm{AgCl}$ surface electrodes ( $44 \times 30 \mathrm{~mm}$; SORIMEX, Poland) were distributed to the muscle fibre direction of $\mathrm{VMO}$ and RF muscles of the right and left lower extremity, according to the method for electrode placement for surface EMG recordings in lower limb muscles described by Rainoldi et al. (2004) (Figure 1). The skin under the electrodes was cleaned with a 95\% alcohol solution. The measurements performed complied with SENIAM standards.

Prior to data collection, each participant performed a 10 min dynamic warm-up including squats and jumps. After the warm-up subjects were asked to assume a half squat position (knees bent at $60^{\circ}$, hips bent at $60^{\circ}$ ) (Figure 2).

The sEMG data were collected while the 
subjects performed an isometric test in the half squat position for $60 \mathrm{~s}$. Median frequency (MF) was compared between the $1^{\text {st }}$ and the last second of the test. The percentage decrease of the median frequency was used for further analysis. Dynamics of the median frequency during the whole test was obtained by a short-time Fourier transformer.

The IBM SPSS STATISTICS programme was used for statistical analysis. To compare variables between the two groups (PFPS group vs. controls), the Mann-Whitney $U$ test was used. Statistical significance was accepted at $p<0.05$ unless otherwise stated.

\section{Results}

There were no significant differences $(p>$ 0.05 ) in age, body height and mass between the PFPS group and controls (Table 1).

Following MF analysis, significant differences between the two groups were found in right and left $\mathrm{VMO}$ muscles and the right $\mathrm{RF}$ muscle $(p \leq 0.01)$. A significant difference between the two groups was also found in the left RF muscle $(p \leq 0.05)$ (Table 2).

A greater percentage decrease in MF of the sEMG signal for all muscle groups was observed in runners with PFPS in comparison to the controls.

\begin{tabular}{|c|c|c|c|c|c|c|c|c|}
\hline \multicolumn{9}{|c|}{$\begin{array}{c}\text { Table } \mathbf{1} \\
\text { Average ( } \pm \text { SD) age, body height, body mass, training frequency and running experience } \\
\text { in the PFPS group and controls }\end{array}$} \\
\hline Group & $\mathrm{n}$ & Male & Female & $\begin{array}{c}\text { Age } \\
\text { (years)* }^{*}\end{array}$ & $\begin{array}{l}\text { Body } \\
\text { height } \\
(\mathrm{cm})^{*}\end{array}$ & $\begin{array}{l}\text { Body } \\
\text { mass } \\
(\mathrm{kg})^{*}\end{array}$ & $\begin{array}{l}\text { Average } \\
\text { training } \\
\text { frequency }\end{array}$ & $\begin{array}{l}\text { Average } \\
\text { running } \\
\text { experience }\end{array}$ \\
\hline $\begin{array}{l}\text { PFPS } \\
\text { group }\end{array}$ & 20 & 15 & 5 & $27 \pm 5$ & $173 \pm 6$ & $69 \pm 6$ & $\begin{array}{l}2 \text { times/ } \\
\text { week }\end{array}$ & 3 years \\
\hline Controls & 20 & 15 & 5 & $26 \pm 4$ & $175 \pm 5$ & $71 \pm 5$ & $\begin{array}{l}2 \text { times/ } \\
\text { week }\end{array}$ & 3 years \\
\hline \multicolumn{9}{|c|}{ * no significant differences between groups $(p>0.05)$} \\
\hline
\end{tabular}

\begin{tabular}{|c|c|c|c|c|c|c|}
\hline \multicolumn{7}{|c|}{$\begin{array}{c}\text { Table } 2 \\
\text { Percentage decrease of the median frequency during the sEMG measurement in the half squat position }\end{array}$} \\
\hline & \multicolumn{2}{|c|}{$\begin{array}{l}\text { Decrease of MF in } \\
\text { the PFPS group (\%) }\end{array}$} & \multicolumn{2}{|c|}{$\begin{array}{l}\text { Decrease of MF in the } \\
\text { control group (\%) }\end{array}$} & \multirow{2}{*}{ Z } & \multirow{2}{*}{$p$} \\
\hline & M & SD & $\mathrm{M}$ & SD & & \\
\hline VMO right & 8.51 & 2.58 & 4.06 & 1.37 & $-4.626^{* *}$ & 0.001 \\
\hline VMO left & 7.23 & 2.59 & 4.25 & 1.74 & $-3.625^{* *}$ & 0.001 \\
\hline RF right & 4.64 & 1.37 & 3.23 & 1.41 & $-3.383^{* *}$ & 0.001 \\
\hline RF left & 4.40 & 1.99 & 2.79 & 1.57 & $-2.490^{*}$ & 0.013 \\
\hline \multicolumn{7}{|c|}{${ }^{*} p \leq 0.05 ;{ }^{* *} p \leq 0.01$} \\
\hline
\end{tabular}



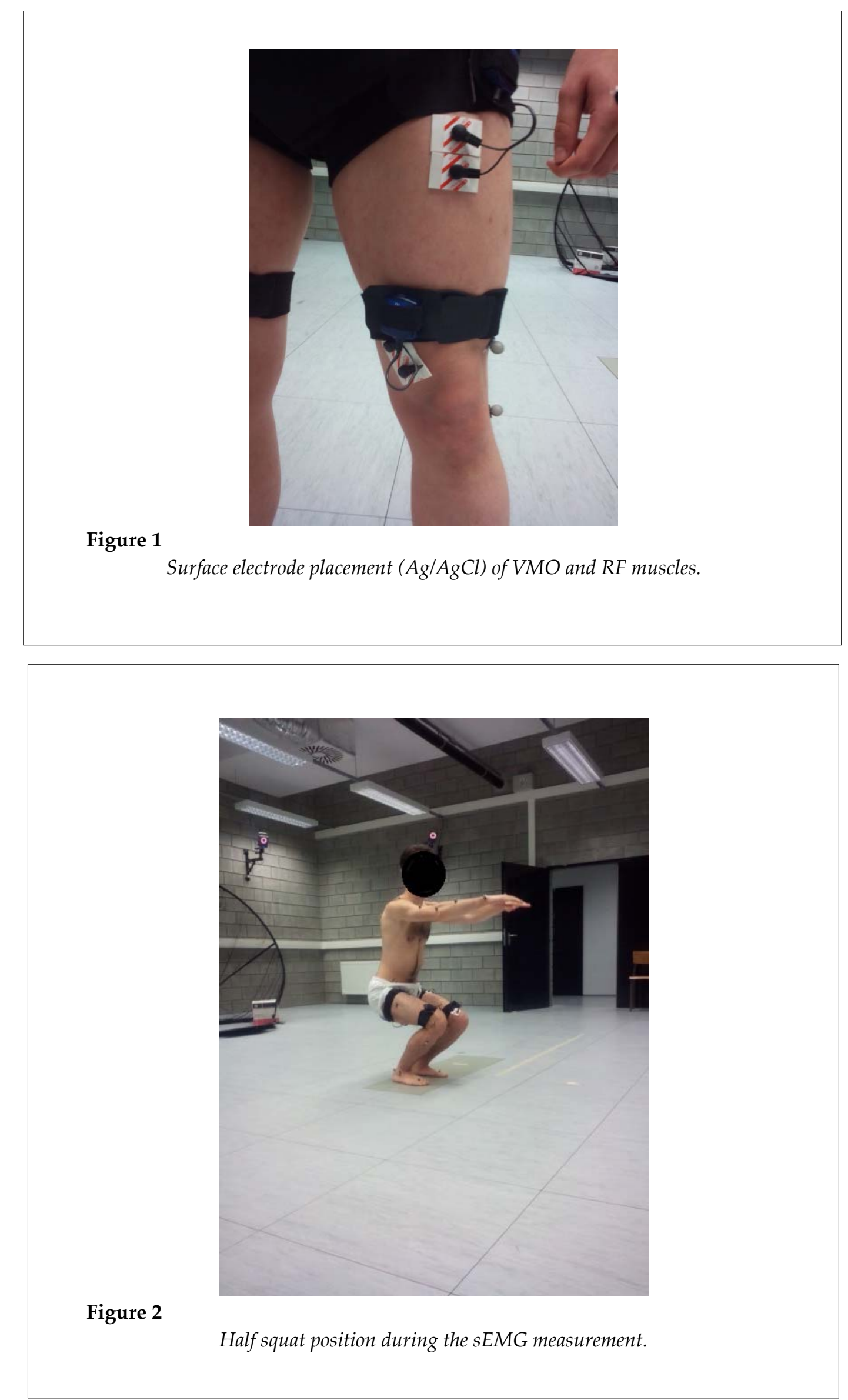


\section{Discussion}

The main purpose of this study was to determine the differences in bioelectric activity of VMO and RF muscles during the half squat position in runners with PFPS in comparison to healthy controls. In this study the PFPS group showed a significantly greater decrease of the median frequency of VMO and RF muscles activity during the sEMG measurement in the half squat position. Muscle activity studied during isometric exercises allows for non-invasive examination of muscle fatigue. Analysis of the sEMG frequency measured in the isometric position may provide a basis for determining the fatigue and endurance level of the examined muscle groups. A decrease in sEMG median frequency during isometric contraction may be a symptom of muscle fatigue (Mello et al., 2015; Niederer et al., 2016; Rainoldi et al., 2008). Thus, in our study, sEMG median frequency analysis was used to determine the differences in muscle activity between subjects with PFPS and controls.

Previous studies based on electromyographic measurements have shown that anterior knee pain in subjects with PFPS is related to an imbalance in lower limb muscles (Coqueiro et al., 2005; Laprade et al., 1998). Differences in muscle activity between subjects diagnosed with PFPS and control groups were demonstrated also by Callaghan et al. (2001), Kalytczak et al. (2016) and Miao et al. (2015). Kalytczak et al. (2016) observed that the subjects with PFPS exhibited a significant increase in the EMG activity of the biceps femoris and vastus lateralis (VL) muscles when compared with healthy individuals during the single leg triple hop test. In addition, Miao et al. (2015) showed that the muscle imbalance between the VMO and VL muscles existed in subjects with PFPS and could be one of the main factors leading to the development of PFPS. Callaghan et al. (2001) reported much larger variability of MF values of the VMO muscle in the PFPS group in comparison to controls. In agreement with the above published data, our results also showed a relationship between a greater decrease of MF values of the VMO muscle and presence of PFPS. In relation to the RF muscle, significant differences in MF were not found in the study by Callaghan et al. (2001), which is contrary to our study, where a significant difference between the two groups was also found in the RF muscle. According to our results, this indicates that not only the muscular imbalance between VMO and VL may cause PFPS, but also decreased RF resistance may be a predictor of PFPS. However, further electromyographic studies are needed to determine the activity of all muscle groups of the lower limb in runners with PFPS. It may be beneficial to develop rehabilitation exercises and preventive measures in runners exposed to knee stress.

However, there are not enough publications on selective strengthening of the quadriceps muscle of the thigh. The use of quadriceps strengthening is recommended by Giles et al. (2013) as part of a rehabilitation program for PFPS. In addition, muscle strengthening based on VMO and VL rebalancing could reduce pain symptoms in subjects with PFPS (dos Santos et al., 2013). Moreover, a double-leg semi-squat for VMO strengthening is a common exercise used in the rehabilitation of PFPS (Bolgla and Malone, 2005). Earl et al. (2001) reported also that performing mini-squats with hip adduction may be beneficial to patellofemoral patients as they increase quadriceps activity. Both Tang et al. (2001) and Miao et al. (2015) indicated that a more selective activation of the VMO muscle can be obtained at $60^{\circ}$ knee flexion compared with other angles. Based on these results it can be concluded that a semi-squat at $60^{\circ}$ knee flexion is desirable and safe exercise not only for EMG evaluation, but also for rehabilitation in runners with PFPS. Hence, this angle has been used in our study to evaluate muscle activity. However, the effect of the semisquat exercise on VMO muscle strength and reduction of PFPS symptoms should be examined in further studies. Moreover, it seems appropriate to stress the direction of future research on the exercise of the entire limb with a particular emphasis on training of hamstring muscles.

In addition, rehabilitation methods such as knee taping, neuromuscular electrical stimulation (NMES), and proprioceptive neuromuscular facilitation (PNF) techniques have been found to be effective in elimination of knee pain associated with PFPS (Alba-Martín et al., 2015; Logan et al., 2017; dos Santos et al., 2013). Therefore, it is recommended to use these methods as additional treatment to traditional exercise therapy for PFPS. 


\section{Conclusions}

There is a relationship between knee pain related to PFPS and the imbalance of bioelectric activity of vastus medialis and rectus femoris muscles. Achieving muscular balance within the thigh muscles can be an important factor in the rehabilitation process of PFPS.

\section{Practical implications}

A practical application of this study is that both the VMO and RF muscles should be strengthened to enhance their endurance capability, which may be useful in the prevention and treatment of PFPS.

\section{Acknowledgements} journal.

The results of the present study do not constitute endorsement of the product by the authors or the

\section{References}

Alba-Martín P, Gallego-Izquierdo T, Plaza-Manzano G, Romero-Franco N, Núñez-Nagy S, Pecos-Martín D. Effectiveness of therapeutic physical exercise in the treatment of patellofemoral pain syndrome: a systematic review. J Phys Ther Sci, 2015; 27: 2387-2390

Blønd L, Hansen L. Patellofemoral pain syndrome in athletes: a 5.7-year retrospective follow-up study of 250 athletes. Acta Orthop. Belg, 1998; 64: 393-400

Bolgla L, Malone T. Exercise Prescription and Patellofemoral Pain: Evidence for Rehabilitation. J. Sport Rehabil, 2005; 14: 72-88

Callaghan MJ, McCarthy CJ, Oldham JA. Electromyographic fatigue characteristics of the quadriceps in patellofemoral pain syndrome. Man. Ther, 2001; 6: 27-33

Carry PM, Kanai S, Miller NH, Polousky JD. Adolescent Patellofemoral Pain: A Review of Evidence for the Role of Lower Extremity Biomechanics and Core Instability. Orthopedics, 2010; 33: 498-507

Cheung RTH, Ng GYF, Chen BFC. Association of footwear with patellofemoral pain syndrome in runners. Sports Med. Auckl. NZ, 2006; 36: 199-205

Cichanowski HR, Schmitt JS, Johnson RJ, Niemuth PE. Hip strength in collegiate female athletes with patellofemoral pain. Med. Sci. Sports Exerc, 2007; 39: 1227-1232

Coqueiro KRR, Bevilaqua-Grossi D, Bérzin F, Soares AB, Candolo C, Monteiro-Pedro V. Analysis on the activation of the VMO and VLL muscles during semisquat exercises with and without hip adduction in individuals with patellofemoral pain syndrome. J. Electromyogr. Kinesiol. Off. J. Int. Soc. Electrophysiol. Kinesiol, 2005; 15: 596-603

Dixit S, DiFiori JP, Burton M, Mines B. Management of patellofemoral pain syndrome. Am. Fam. Physician, 2007; 75: 194-202

Domenech J, Sanchis-Alfonso V, López L, Espejo B. Influence of kinesiophobia and catastrophizing on pain and disability in anterior knee pain patients. Knee Surg. Sports Traumatol. Arthrosc. Off. J. ESSKA, 2013; 21: $1562-1568$

Earl JE, Schmitz RJ, Arnold BL. Activation of the VMO and VL during dynamic mini-squat exercises with and without isometric hip adduction. J. Electromyogr. Kinesiol. Off. J. Int. Soc. Electrophysiol. Kinesiol, 2001; 11: 381-386

Giles LS, Webster KE, McClelland JA, Cook J. Does quadriceps atrophy exist in individuals with patellofemoral pain? A systematic literature review with meta-analysis. J. Orthop. Sports Phys. Ther, 2013; 43: 766-776

Hart JM, Pietrosimone B, Hertel J, Ingersoll CD. Quadriceps activation following knee injuries: a systematic review. J Athl Train, 2010; 45: 87-97

Jones PA, Bampouras TM. A comparison of isokinetic and functional methods of assessing bilateral strength imbalance. J Strength Cond Res, 2010; 24: 1553-1558 
Kalytczak MM, Lucareli PRG, Dos Reis AC, Bley AS, Biasotto-Gonzalez DA, Correa JCF, Politti F. Kinematic and electromyographic analysis in patients with patellofemoral pain syndrome during single leg triple hop test. Gait Posture, 2016; 49: 246-251

Knapik JJ, Bauman CL, Jones BH, Harris JM, Vaughan L. Preseason strength and flexibility imbalances associated with athletic injuries in female collegiate athletes. Am J Sports Med, 1991; 19: 76-81

Lankhorst NE, Bierma-Zeinstra SMA, van Middelkoop M. Risk factors for patellofemoral pain syndrome: a systematic review. J. Orthop. Sports Phys. Ther, 2012; 42: 81-94

Laprade J, Culham E, Brouwer B. Comparison of five isometric exercises in the recruitment of the vastus medialis oblique in persons with and without patellofemoral pain syndrome. J. Orthop. Sports Phys. Ther, 1998; 27: 197-204

Liporaci RF, Saad MC, Felício LR, Baffa AP, Grossi DB. Contribution of the evaluation of the clinical signals in patients with patellofemoral pain syndrome. Acta Ortop. Bras, 2013; 21: 198-201

Logan CA, Bhashyam AR, Tisosky AJ, Haber DB, Jorgensen A, Roy A, Provencher MT. Systematic Review of the Effect of Taping Techniques on Patellofemoral Pain Syndrome. Sports Health, 2017; 9: 456-461

Mello RGT, Carri IR, da Matta TT, Nadal J, Oliveira LF. Lumbar multifidus and erector spinae electromyograms during back bridge exercise in time and frequency domains. J. Back Musculoskelet. Rehabil, 2015; 29: 123-133

Miao P, Xu Y, Pan C, Liu H, Wang C. Vastus medialis oblique and vastus lateralis activity during a double-leg semisquat with or without hip adduction in patients with patellofemoral pain syndrome. BMC Musculoskelet. Disord, 2015; 16: 289

Niederer D, Vogt L, Pippig T, Wall R, Banzer W. Local Muscle Fatigue and 3D Kinematics of the Cervical Spine in Healthy Subjects. J. Mot. Behav, 2016; 48: 155-163

Nunes GS, Stapait EL, Kirsten MH, de Noronha M, Santos GM. Clinical test for diagnosis of patellofemoral pain syndrome: Systematic review with meta-analysis. Phys. Ther. Sport Off. J. Assoc. Chart. Physiother. Sports Med, 2013; 14: 54-59

Raid DC. The Myth, Mystic, and frustration of Anterior Knee Pain. Clin. J. Sport Med, 1993; 3: 139

Rainoldi A, Melchiorri G, Caruso I. A method for positioning electrodes during surface EMG recordings in lower limb muscles. J. Neurosci. Methods, 2004; 134: 37-43

Rainoldi A, Falla D, Mellor R, Bennell K, Hodges P. Myoelectric manifestations of fatigue in vastus lateralis, medialis obliquus and medialis longus muscles. J Electromyogr Kinesiol, 2008; 18: 1032-1037

Reilly DT, Martens M. Experimental analysis of the quadriceps muscle force and patello-femoral joint reaction force for various activities. Acta Orthop. Scand, 1972; 43: 126-137

dos Santos RL, Souza MLSP, dos Santos FA. Neuromuscular electric stimulation in patellofemoral dysfunction: literature review. Acta Ortop. Bras, 2013; 21: 52-58

Schoenfeld BJ. Squatting kinematics and kinetics and their application to exercise performance. J. Strength Cond. Res, 2010; 24: 3497-3506

da Silva JCL, Tarassova O, Ekblom MM, Andersson E, Rönquist G, Arndt A. Quadriceps and hamstring

muscle activity during cycling as measured with intramuscular electromyography. Eur J Appl Physiol, 2016; 116: 1807-1817

Simões EC, Moraes AC, Okano AH, Altimari LR. Behavior of emg activation of rectus femoris, vastus lateralis and vastus medialis muscles during maximum contraction before and after a series of repeated efforts. Electromyogr. Clin. Neurophysiol, 2008; 48: 377-384

Souza RB, Powers CM. Differences in hip kinematics, muscle strength, and muscle activation between subjects with and without patellofemoral pain. J Orthop Sports Phys Ther, 2009; 39: $12-19$

Stefanyshyn DJ, Stergiou P, Lun VMY, Meeuwisse WH, Worobets JT. Knee angular impulse as a predictor of patellofemoral pain in runners. Am J Sports Med, 2006; 34: 1844-1851 
Tang SF, Chen CK, Hsu R, Chou SW, Hong WH, Lew HL. Vastus medialis obliquus and vastus lateralis activity in open and closed kinetic chain exercises in patients with patellofemoral pain syndrome: an electromyographic study. Arch Phys Med Rehabil, 2001; 82: 1441-1445

Yosmaoglu HB, Kaya D, Guney H, Nyland J, Baltaci G, Yuksel I, Doral MN. Is there a relationship between tracking ability, joint position sense, and functional level in patellofemoral pain syndrome? Knee Surg. Sports Traumatol. Arthrosc. Off. J. ESSKA, 2013; 21: 2564-2571

\section{Corresponding author:}

\section{Michał Ginszt}

Department of Rehabilitation and Physiotherapy, Chair of Rehabilitation, Physiotherapy and Balneotherapy, Faculty of Health Sciences, Medical University of Lublin, Poland

ul. Magnoliowa 2

20-143 Lublin, Poland

$+48602533723$

michal.ginszt@umlub.pl 